\title{
Supply Chain Dynamics, a Case Study on the Structural Causes of the Bullwhip Effect ${ }^{1}$
}

\author{
F. Villegas-Morán, O. Carranza y J.P. Antún \\ $O$ perations $M$ anagement, $M$ anchester Busines $S$ chool. University of Manchester, UK. \\ Universidad Panamericana, M éxico e Instituto de Ingeniería, UN AM \\ E-mails: fvillegas@man.mbs.ac.uk,ocarranz@mx.up.mxy jpantun@iingen.unam.mx
}

(recibido: febrero de 2005; aceptado: junio de 2005)

\begin{abstract}
Resumen
Este artículo es un caso de estudio sobre el modelado de la estructura de toma de decisiones de la cadena de suministro de una embotelladora en México. Al modelar las cadenas de suministro de esta manera, es posible identificar las políticas gerenciales y los flujos de informacion que introducen y amplifican distorsiones en la demanda. En la segunda parte de este artículo, utilizamos dos escenarios para analizar posibles modificaciones en las políticas de dirección. Este trabajo ilustra no sólo una innovadora forma de estudiar el efecto látigo, o una forma distinta de modelar las cadenas de suministro usando los principios de dinámica de sistemas, sino que también establece una relación entre la estructura de información, las políticas de los gerentes y las distorsiones en la cadena de suministro.
\end{abstract}

Descriptores: Dinámica de sistemas, cadenas de suministro, caso de estudio, efecto látigo.

\begin{abstract}
This is a case study about the mod el ling of a sup ply chain de ci sion struc ture of a M ex i can bottling com pany. Wefind that by mod el ling thein for ma tion and deci sion structure of sup ply chains, it is possi bletoiden tify man a gerial pol i ciesand in for ma tion flows that distortand am plify mar ket demand sig nals. In thesecond part of thepa per weusetwo scenar ios to ana lysevar $i$ ous chan ges in pol i cies. This pa per il lus trate not only an in no va tiveform to study theBull whip Ef fect nor only a dif fer ent way to model sup ply chains using $S$ ys tem D y nam ics, but also it es tab lishes a rela tion ship between in for ma tion structures, deci sions rules, and demand dis tor tion in sup ply chains.
\end{abstract}

Keywords: System dy nam ics, sup ply chain man agement, casestudy, bull whip ef fect.

\section{Introduction}

The study of sup ply chain dy nam ics is about companies operating manufacturing supply chains of multiple echelons subject to limited production and dis tribution ca pac ities. At each ech e lon, operation man ag ers re ceive or ders froma down stream ech e lon and try to ful fil them by tak ing two de cisions: shipping from available inventory, and ordering more products to the echelon upstream. Order policies are based on experience, opera- tional strategy and information availability. Order fulfilment is constrained by production capacity, transportation capacity and inventory availability. Sup ply chain sys tems have mainly two time de lays:

1 Por razones de confidencialidad, los datos referidos en este artículo (a excepción de los públicos) han sido modificados. Por tanto, este modelo no refleja forzosamente la realidad del negocio en cuestión. Sin embargo, sentimos que esas modificaciones no afectan la validez científica de la investigación. 
orders are communicated with information time de lays, and they are ful filled with op er a tional time delays too (e.g., production and delivery). The supply chain dynamics problem consists in that given a set of order pol i cies from man ag ers at each echelon, market demand signals will be distorted and amplified (the Bullwhip Effect) through the echelons. The objective of supply chain dynamics problems is to minimize operational costs derived from those distortions and amplifications by improvingmanagersorderpolicies.

In the context of the supply chain dynamics problem, Forrester (1962), and Sterman (1989, 2000), have explored the impact of time delays. Lee et al. (1997a, 1997b) have ex plored the im pact that batching, price discounts, rationing expecta tions and forecasting, have in the definition of order policies that lead to distortions of market demand signals. Towill et al. (1991, 1995), Naim et al. (2002) and Dejonckheere et al. (2002, 2003, 2004) have used an approach based on optimal con trol the ory to find con trol pol i cies to smooth the bull whip ef fect.

However, Forrester and Sterman's approaches fall short of study the supply chain dynamics because they use a predefined flow of information and management rules which are not longer valid for com pa nies that use in forma tion sys tems. Towill et al. (1996, 2000), Dejonckheereet al. (2002, 2003, 2004) as sume flow con ti nu ity for the sup ply chain sys tem in time, and that the sup ply chain pol i cies can be always reduced to a set of partial dif fer en tial equa tions that can be solved. As we know, this is not the case of real sup ply chains that are typ ically non-linear partial differential equations of higher order. Lee et al. (1997a, 1997b) did not suggest any new set of policies to improve the supply chains dy nam ics be hav iour re sponse.

PepsiCo has two divisions, Pepsi Cola North America, for the US, and PepsiCo BeveragesInternational, for the rest of the world. In 2003, Pepsi-Cola North America (PCNA) had in crements on volume (4\%), revenue (18\%) and operating profit $(13 \%)$ as indicated in figure 1. PCNA grew faster than its largest competitor. In fact, PCNA gained share while Coca-Cola share de clined. They are sure that innovation was the driver of that growth, because in fact PCNA brought an array of new prod ucts to the mar ket place.

Much of that innovation focused on carbonated soft drinks (Figure 2). Pepsi Twist, which is Pepsi with a hint of lemon, helped the growth in their cola business. Within 30 days of launching Pepsi Twist in the US, Pepsi bot tlers had sold more than 10 million cases. In addition, in its first full year on the mar ket, lemon-lime Si erra Mist gen erated healthy sales and, where it was avail able, drove growth in the lemon-lime category. Meanwhile, Mountain Dew Code Red contributed to strong Moun tain Dew growth of $6 \%$.

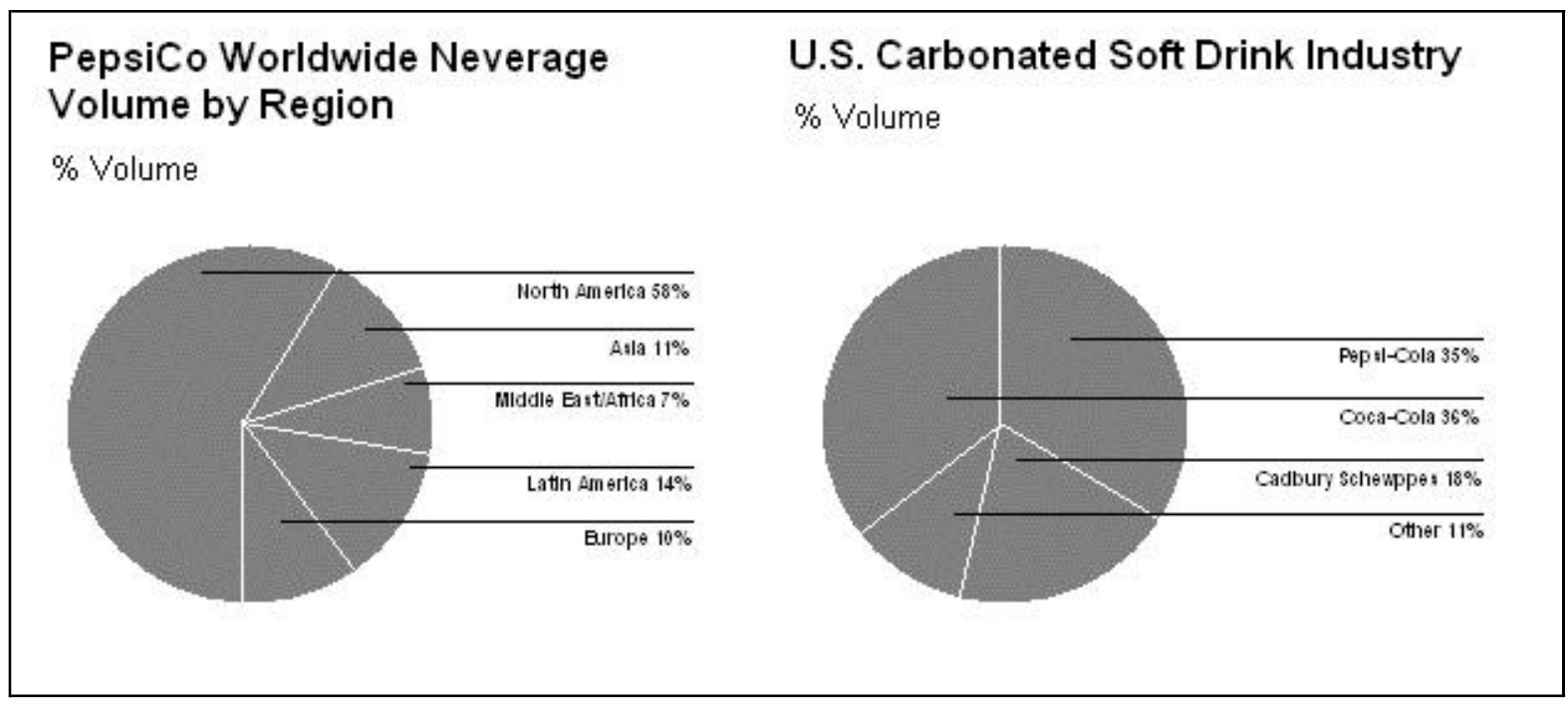

Figure 1: EM SA, PepsiCo worldwide beverage volume by region (Source: Annual report 2002) 


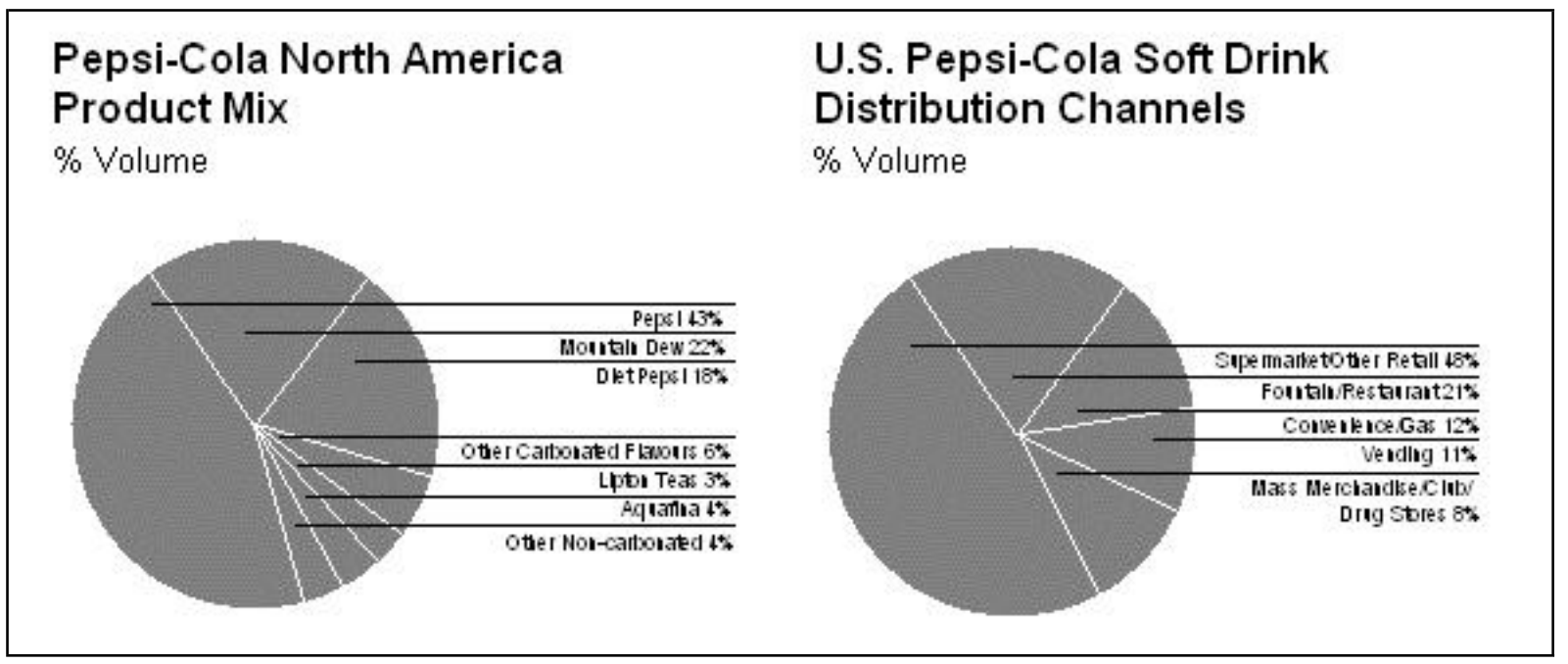

Figure 2: EM SA, Pepsi-Cola North America product mix and channels(Source: Annual report 2002)

While traditional carbonated soft drinks account for the bulk of beverage volume, as consumers seek greater variety, their non-carbonated drinks have been growing very rapidly, with volume up more than $30 \%$ in 2001 . In fact, over the last decade they have built the leading portfolio of non-carbonated drinks (Figure 3) - including Aquafina bot tled water, Lipton ready-to-drink teas, Frappuccino coffee drinks, Dole juices and drinks and SoBe beverages.

Aquafina is already the top-selling single-serve bot tled water in the US. On the year of its in tro duction (2001), it vol ume grew about $45 \%$. The launch of a new bot tle helped PCNA growth of more than $20 \%$ in Lipton Iced Tea. And additional volume growth came from products under the Dole and SoBe brands. PCNA's goal is to continue to improve its position in the market (Figure 4) to be come the fastest growing broad-based beverage com pany. For this strat egy it is cen tral to keep the con tin u ous expan sion of its prod uct port fo lio.

PCNA, working with Frito-Lay North America (FLNA), also added excitement with awarded mar keting campaigns in 27 urban centres across the U.S. They included merchandising, promotions and ad vertis ing that cap tured the at ten tion of African-American and Latino consumers. PCNA and FLNA activated more than 5,500 accounts and achieved vol ume gains of more than $25 \%$ in par tic ipat ingstores.

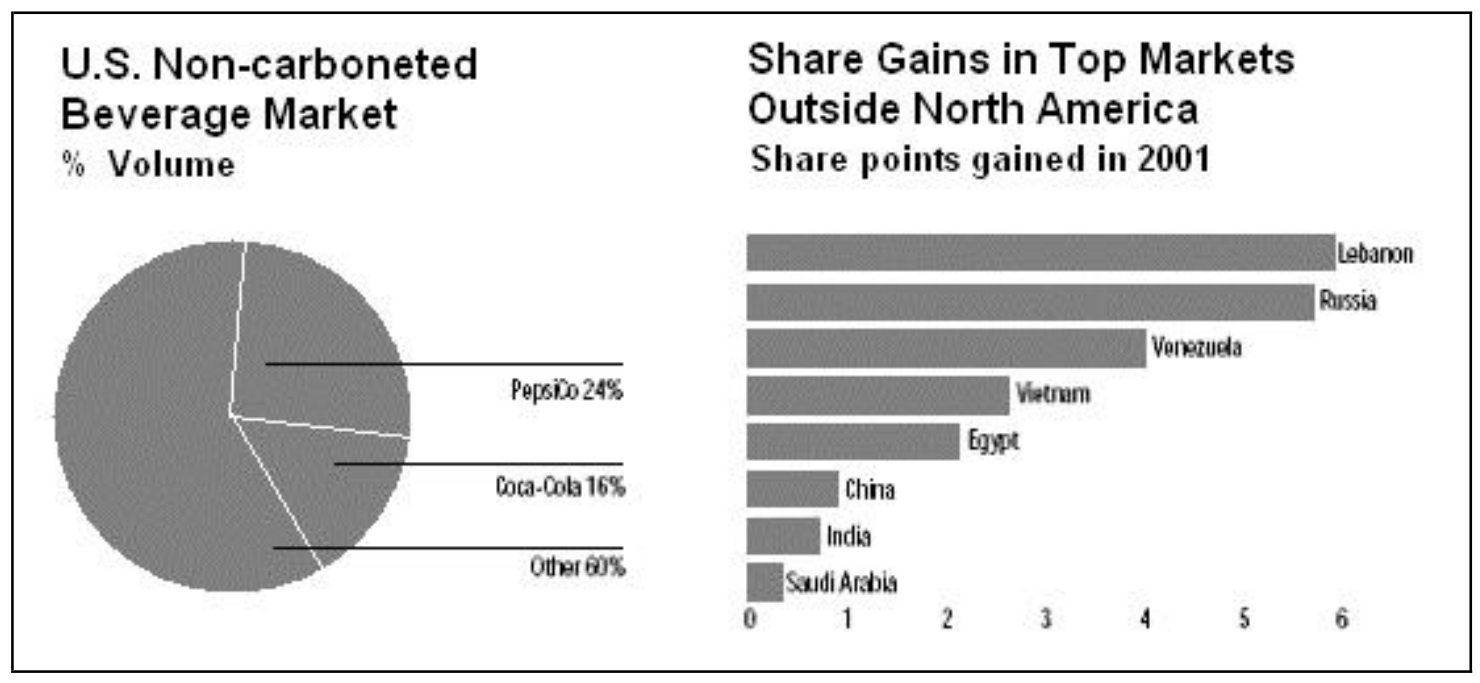

Figure 3. EM SA, U.S. N on-carbonated beverage market (Source: Annual report 2002) 


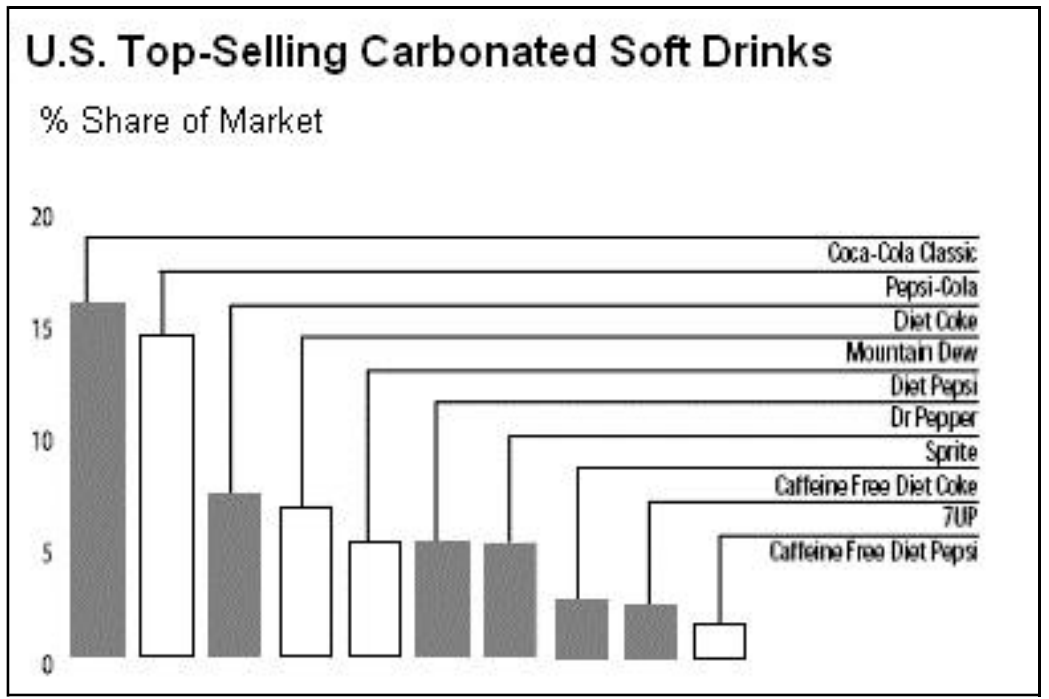

Figure 4: EMSA, U.S. Top-selling carbonated soft drinks (Source: Annual report 2002)

PepsiCo Beverages International (PBI), formed after the PepsiCo-Quaker merger by com bin ing the in ter national operations of Pepsi-Cola, Gatorade and Tropicana, posted a solid performance in its first year. Vol ume was up nearly $5 \%$ (Table 1 ), matching their largest competitor. Revenue was up $2 \%$. Operat ing profit was up $31 \%$.

Table 1: EM SA, Pepsi-Cola N orth A merica operating profits (Source: Annual report 2002)

\begin{tabular}{|c|c|c|c|c|c|}
\hline \multicolumn{4}{|c|}{ Pepsi-Cola North America } & \multicolumn{2}{|c|}{$\%$ Change $\mathrm{B} /(\mathrm{W})$} \\
\hline & 2001 & 2000 & 1999 & 2001 & 2000 \\
\hline \multicolumn{6}{|l|}{ Net } \\
\hline \multicolumn{6}{|l|}{ Sales } \\
\hline Reported & $\$ 3,842$ & $\$ 3,289$ & $\$ 2,605$ & 17 & 26 \\
\hline Comparable & $\$ 3.842$ & $\$ 3,253$ & $\$ 3,005$ & 18 & 8 \\
\hline \multicolumn{6}{|l|}{ Operating profit } \\
\hline Reported & $\$ 927$ & $\$ 833$ & $\$ 751$ & 11 & 11 \\
\hline Comparable & $\$ 927$ & $\$ 820$ & $\$ 751$ & 13 & 9 \\
\hline \multicolumn{4}{|c|}{ PepsiCo Beverages International } & \multicolumn{2}{|c|}{$\%$ Change $B /(\mathrm{W})$} \\
\hline & 2001 & 2000 & 1999 & 2001 & 2000 \\
\hline \multicolumn{6}{|l|}{ Net } \\
\hline \multicolumn{6}{|l|}{ Sales } \\
\hline Reported & $\$ 2,582$ & $\$ 2,531$ & $\$ 2,407$ & 2 & 5 \\
\hline Comparable & $\$ 2,582$ & $\$ 2,531$ & $\$ 2,429$ & 2 & 4 \\
\hline Operating profit & $\$ 221$ & $\$ 169$ & $\$ 108$ & 31 & 56 \\
\hline
\end{tabular}


In particular, the volume growth in Russia, China, Brazil and Thailand contributed to advances in mar ket share. In fact, PBI gained share in most of its top markets, with particular progress in Leb a non, Rus sia, Ven e zuela, Viet nam and Egypt.

Here too, in no va tion was a bigfac tor. Exten sions of the flagship Pepsi trademark helped to drive growth in a variety of local markets. For example, Pepsi Limón and Pepsi Twist - in both cases, Pepsi with a hint of lemon - proved also to be popular in disimilar coun tries such as Mex ico and Saudi Ara bia. The launch of Mountain Dew contributed significantly to growth in Rus sia. And new ad di tions to the established line-up of Mirinda brand flavours were launched in more than 30 mar kets.

During 2003, PBI gained important advantages by bringing together Pepsi-Cola, Gatorade and Tropicana. Combining the general and administrative functions of these busi nesses around the globe yields very sub stan tial cost sav ings. In ef fect, the com bi na tion of Gatorade, Tropicana and Pepsi's water made a powerfulportfolio for a wide range of needs - from simple refreshment to nutrition to post-exercise hydration - for con sum ers aro und the world.

\section{Modelling considerations}

In our case study we work with the main bottler of PepsiCo Beverages International in Mexico: EMSA (Embotelladora Mexicana Sociedad Anónima), which at tend Cen tral Mexico, in clud ing the states of Jalisco and the Bajío. According with its supply chain man ager, EMSA is con sid ered the op era tional stan dard for the rest of Latin Amer ica. We se lected a high sales vol ume prod uct, in this case Pepsi $600 \mathrm{ml}$ which rep re sent al most $40 \%$ of net sales.

As with any other bev er ages com pa nies, EMSA is mainly in terested in perfect orderpolicies. That is, keeping inventories in all possible retailers, since prod uct sub stitu tion against the com petition is very frequent. In their business, product presence at sales point is trans lated into sales.

\section{Purchase manager}

The main raw material for the production of Pepsi-Cola, apart of water of course, is sugar. They purchase sugar based on price. Every year they se lect a small set of sup pli ers from a pool of pos si ble vendors. Sugar price var ies ac cord ing to mar ket. In Mexico most of the producers are state owned. There is a min i mum amount of sugar to buy on a monthly basis of 185Ton. Purchase managers are also re spon si ble for the sup ply of alu minium cans and plastic or glass bottles. Purchase managers generate a supply plan once every month and at least one month in advance. Pepsi uses its own fleet of trucks to pickup the materials from some suppliers. The following is an extract from the in ter views with the pur chase man ager:

"We have two main warehouses per plant: one for raw ma teri als (sugar, la bels, bot tles and cans), and another for Pepsi syrup only. Right now we have US $\$ 1.2 \mathrm{~m}$ in inventories of raw materials. In this ware house, there are com po nents that areman aged against sched uleor ders: la bels, bot tles and cans etc. Wehavea min i mum stock in ven tory pol icy...

We order based on a maxi mumand min i mum with small cor rectionsaccord ing to thereal demand... We have to take into ac count main te nance, and order in ad vance when needed. We have also or ders to be confirmed on a monthly basis. Every week we check our in ven to ries and pay their in voices. $80 \%$ of our purchase is Pepsi syrup and sugar.

When a new product launch hap pens, we have to work closely with designers from PepsiCo M exico. The designs are pro vided from the cor po rateheadquarters, we then forward them to our label suppliers along with an initial pur chaseorder...

My main problems with Logistics are that they never give methe pro duc tion programme!"

\section{Production manager}

When we interviewed the production manager, apart from being proud of their excellenceawards in quality and achievements in re duc ing waste, he pointed out that one of the problems was the ob solescence of product due to shelf life. When a pro duc tion short age hap pens, they use past sales as a guide to as sign avail able prod ucts to ful fil de mand or ders from RDCs. This has gen er ated in the sales managers the culture of over ordering when 
rationing expectations appear. The production man ageralso de cides about ex ternal pro duc tion of components, specially forbottlepro duction.

"I am based very much on stock po si tions in thein forma tion system. M ainly, I look at in ven tory po si tions in warehouses or CEDIS (CEntro deDIS tri bu tion). I have my own policy of inventories. I always try to follow my pol icy, which is op ti mal. I look at the inven to ries once a week and from there I make a weekly plan: How much do I require for every prod uct for the next week based on my forecast and stock position? H ow much is my ex cess or short age?... then I decide if I need to pro duce many or a few.

Now, in [the case of] plas tic and glass bot tled products, becausewenever havehigh [ex pen sive] in ventories, I need to be very flexible in scheduling. But that is not the case of cans; [there] I try to make long pro duction runs per week. In this way I can op ti mize the num ber of changes and set ups, for dif fer ent flavours and sizes... [therefore] scrap is reduced... if I make many changes and setups, scrap is produced... [that is why] my in ten tion is to make long runs each week".

\section{Sales managers}

They have all the market information in a system called SIME (Sistema de Informacion de MErcado), customer by customer. They have more than 150,000 sales points. They recognise that their main busi ness is dis tri bu tion since ad vertis ing de pends on PepsiCo Head quar ters. The av er age level of education reached by a salesman is secondary school. In principle, the forecast is produced by operational managers using econometric standards, and the sales managers are responsible of fine tune it with expected demand volumes per zone and by prod uct. The sales man ag ers do not follow the bottom up approach to create a forecast, because of previous experience, where demand was exag ger ated by sales men in an ac cu mula tive per cent age of $80 \%$, driven by the in stinct to ensureproductavailability.

"... A bout fore cast... I be lieve that we never fol low them... some time ago production used to supply us everything that we ordered, what the market needed and we sold, but later pro duc tion asked for a more pre cise fore cast and they asked us to make a more precise predic tion. We pro duced that fore cast for 4 or 5 months directly, creating the forecast from our sales estimations based on the "last month sales" and we multiplied it by a factor month by month... together with past sales and new sale expectationswe produced a forecast by space, brand, ware house, fla vours... we then sent that forecast to production... our accuracy was around $96 \%$ with some fail ures in fla vours... some times boys [salesmen] required more orange than apple fla vours and then again we had some complaints from production. Wefi nally agree that fore casting was going to be again a responsibility of production, but under the as sess ment of the sales department... that they make it, but asking us and comparing against our own expectations... since then we have not followed this initiative properly... as I told you about fore casts, they know it very well, but up to now, we do not have well solved who is in charge of forecasts... they never call us to validate the fore cast... that is what we have to im prove!...

Everything goes together with sales... if we do not have the product we can not sell... the chal lenge of production is to pro duceall thenec es sary prod ucts (packages, labels) in order to send the products on time to reach warehouse early and then the salesman can take the prod uct and de liver it to our customers as it should be: high quality, good image, good con di tions of bot tles, etc... I be lieve that produc tion used to do a good job, same as sales... we have lots of things to im prove."

\section{Logistics manager}

Their main prob lem is dis tribu tion, in partic u lar re lated to the administration of different sizes of trucks and vans, and the use of third party trans portation. The logistics managers do not have a clear vi sion about which RDCs can re ceive full size trucks, but they know that inter-plants can re ceive double-sized trucks. They are trying to use the in-house fleet as much as possiblebut with out replacing them, due to a strategy to move from owned trucks to third party transportation. His performance is mea sured in relation with thetranspor ta tion cost (per prod uct unit), and the av er age ca pac ity loaded per truck (\% load/ca pac ity). 


\section{Model description}

Given the nature of the System Dynamics methodology (Sterman 2002; Lane 2001; Doyle and Ford 1998), the model will not emphasise the de tail of the Supply Chain network. SD models are abstractions that concentrate the attention not in a detailed modelling of the reality but in the cause-effect and feedback loops that generatea given behaviour. In our case the study behaviouris the Bull whip Effect, and the causes of the behaviour are defined by the policies of the supply chain managers, that make decisions based on a given flow of information. Therefore, the model is limited in detail but not in meaning since our analysis of distortions is of an aggregated nature. Particularly, a model of this na ture does not need to de tail mul ti ple plants or DCs and products to analyze the information use and decision making pro cess of man agers.

The model lays emphasis on the modelling of poli cies of the sup ply chain man ag ers that may be based on their own experience or knowledge. We make explicit the use of information flows and their sources. The model shows the avail abil ity and reliability of the in for ma tion through the in forma. tion sys tems used by the busi ness. The model can also be used to an a lyze the con gru ency of de ci sion makers with respect the in for mation systems.

We have selected for model validation and calibration (parameterization) the historic demand for the year 2002. Based on this demand we have modelled the supply chain dynamics by including heuristic policies as described by the supply chain managers during our interviews. The model shows the main aggregatedbehaviour of inventories, differences be tween plan and exe cu tion and the re sult ing service level. The decision making happens at the be gin ning of every week, when man ag ers look at the in for ma tion sys tems and de cide how much to order upstream. Every event with less that one week dura tion is con sid ered as a simultaneous one for the purposes of the simulation. The time step unit is weeks and all order quantities are in finished goods equivalentunits.

Figure 5 shows the model di a gram for the Pepsi $600 \mathrm{ml}$. Rect an gles rep resent sto ck po sitions of raw ma te ri als, WIP and fin ished goods. As can be seen, in the model we have de fined four stock po si tions in the model: raw ma te rial (RM), work in pro cess (PLANT), finished goods at warehouses (DC) and finished goods in depots (RDC). The raw material

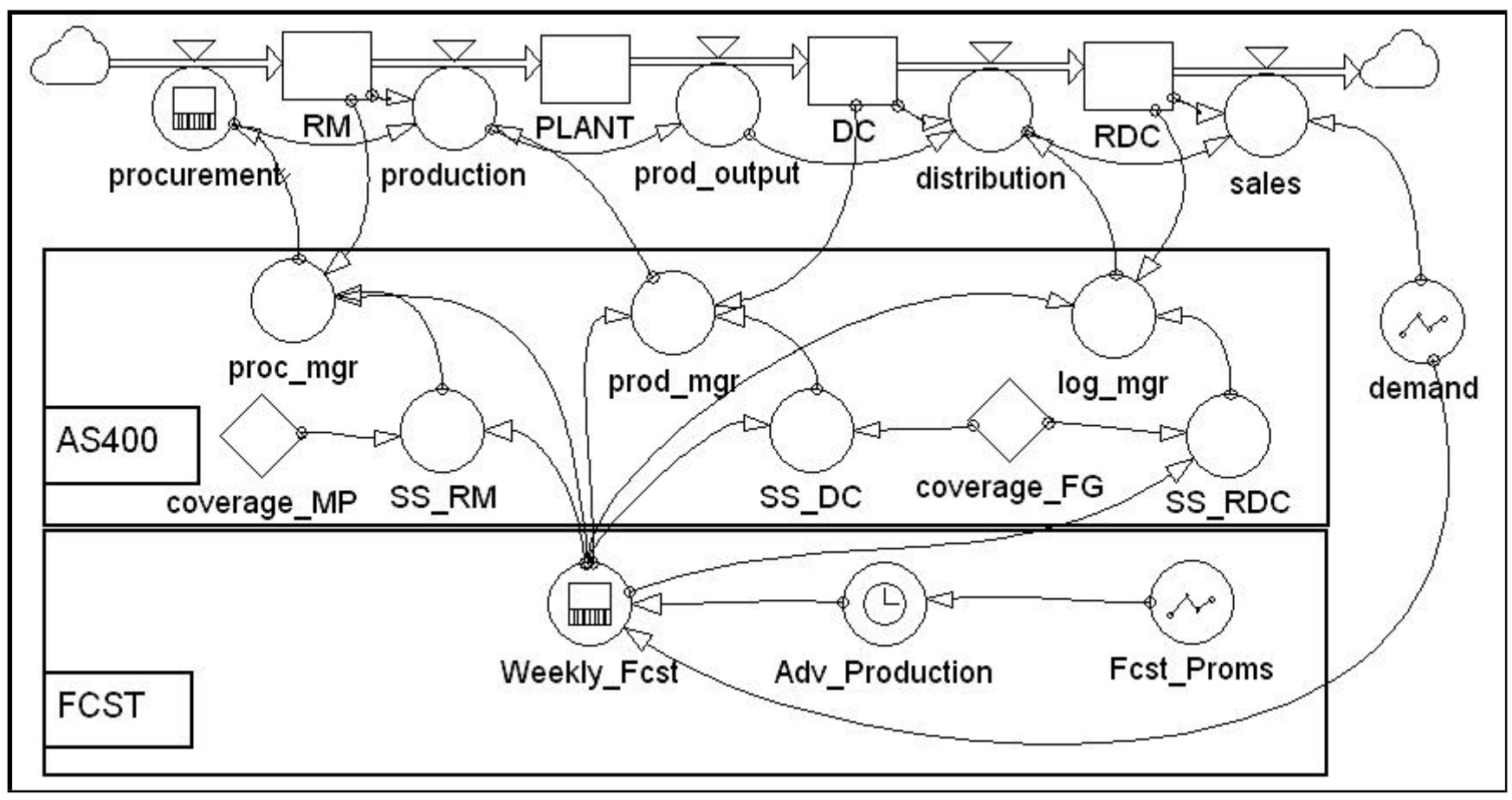

Figure 5: EM SA Supply chain model 
stock units representall the components needed to build one unit of fin ished goods.

Variables are represented with circles, and constants with diamonds. The variable value or constant is communicated to another variable by draw ing a sin gle arrow. So me vari ables rep re sent de cision makers (man agers) and in clude the use of in for ma tion in puts into a func tion that ends with a numerical de cision (e.g., pro duc tion order). Sup ply chain managers are represented by the variables proc_mgr, prod_mgr, and log_mgr. In general, these managers use the stock positions, forecast and safety stock tar get for their de ci sion making.

EMSA operational managers use the term "coverage" to define the safety stock policy defined in terms of forecasted days/weeks of de mand. The safety stock pol i cies, or safety stock target, are constant values. Coverage policies are different for raw materials and finished goods mainly be cause there is a delay of more than one week from pur chase to de liv ery of ma te rials.

Demand forecast is calculated using the last 3 weeks (PastTime) of historic demand and we use them to project the next FutureTime demand according to the FORECAST func tion ex trap o lation that uses expo nen tial smooth ing.

The model groups variables/parameters in two rectangles that represent the information system where the information is allocated. Pepsi-EMSA has an ERP sys tem de rived from IBM's AS400 and an in formal fore cast sys tem based in Excel.

The model can in clude pro mo tional events and the introduction of new products, in such a way that the forecast is not only influenced by past weeks but also by mar ket ing cam paigns. Also some spe cial sea sons where some pro duc tion needs to be allocated in advance to avoid production overload. These ideas are captured by the variables Fcst_Proms and Adv_Production.

Given that our model is con tin u ous, non-linear and fourth degree system, we used a numerical solution method for the analysis. The model is described in mathematical form as follows. First the state vari ables are de fined by:

$$
\begin{aligned}
& R M=\int_{t_{0}}^{t_{1}}(\text { proc } \\
& \text { Factory } \\
& =\int_{t_{0}}^{t_{1}}(\text { production }- \text { prod_output }(t)) d t \\
& D C=\int_{t_{0}}^{t_{1}}\left(\operatorname{prod}_{-} \text {output }(t)-\operatorname{distribution}(t)\right) d t \\
& \text { Retailers }=\int_{t_{0}}^{t_{1}}(\operatorname{distribution}(t)-\text { sales }(t)) d t
\end{aligned}
$$

Rate vari ables are de fined:

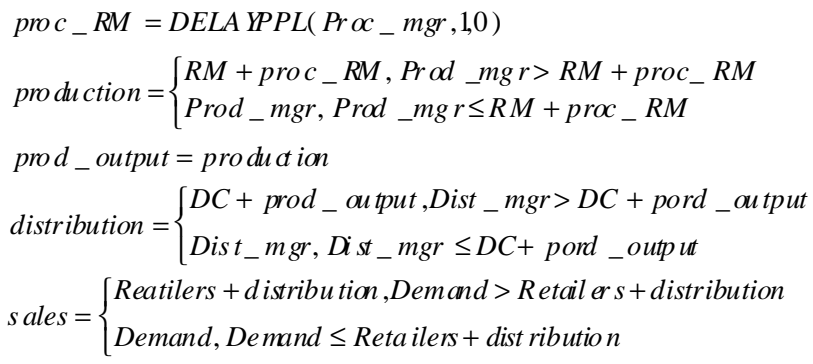

Auxiliaryvariables are:

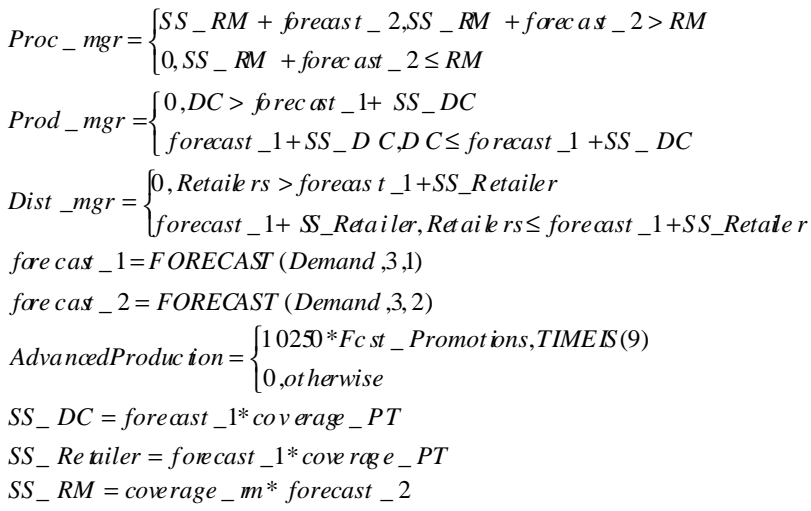

Initialvalues and pa rameters:

$$
\begin{aligned}
& \text { coverage_RM } R M=0.5 \\
& \text { coverage_PT }=0.5 \\
& D C\left(t_{0}\right)=20,000 \text { units } \\
& \text { Factory }\left(t_{0}\right)=0 \text { units } \\
& \text { Retailers }\left(t_{0}\right)=20,000 \text { units } \\
& R M\left(t_{0}\right)=20,000 \text { units }
\end{aligned}
$$

The DELAYPPL func tion is an in fi nite Order Ma te rial Delay. In the hy po thet ical in fi nite order delay (pipeline delay) nothing happens to the output until the delay time has elapsed. At this time the 
input variable is reproduced exactly. A pipeline delay may be looked upon as a "movingsidewalk" or con veyor belt, where items are put on the conveyor at one end, and expelled at the other end after a fixed time.

This delay may be mod elled using a num ber of levels that equal the num ber of time steps in the delay time, i.e., DelayTime/TIMESTEP. In each time step, ma te rial is moved from one level to the next, until it reaches the final level, where it is out put. In Powersim this may be modelled using a vector level, and applying the SHIFTLIF function at each time step to shift elements from one position to the next.

Pipeline delay: Equations of an Infinite Order $\mathrm{Ma}$ te rial Delay if we as sume there are ten steps in a delay time, the equa tions be come:

$$
\begin{aligned}
& \text { aux Input = "Input rate to be de layed" } \\
& \text { init InTransit = "Ini tial con tents of delay" } \\
& \text { dim InTransit }=1 . .10 \\
& \text { flow InTransit( } i)=d t *(\text { Input } \mid i=1 ; 0)-d t * \text { (Out put } \mid \\
& \mathrm{i}=\operatorname{LAST}(\mathrm{i}) ; 0) \\
& \text { aux Out put }=\text { SHIFTLIF(TRUE, InTransit })
\end{aligned}
$$

The function DELAYPPL is used to expressthis kind of delay, we can write di rectly:

$$
\begin{gathered}
\text { aux } \quad \text { Output }=\text { DELAYPPL (Input, } \\
\text { DelayTime, } 0)
\end{gathered}
$$

Syntax: DELAYPPL (Input, DelayTime[, Initial= Input])

Input: Variable to be delayed (delayed parameter).

DelayTime: Delay time mea sured in the time unit of the simulation(start-up parameter).

Initial: Initial delay value (optional start-up pa ram e ter with de fault equal to Input).

Re sult: The value of Input at DelayTime time units earlier in the simulation. During the first DelayTime time units of the sim u la tion, the values specified by Initial are returned (Initial is a vec tor with one el e ment per time step for a pe riod equal to DelayTime).
Diagram: The pipe-line delay, figure 6 , may be modelled using a vector with Delay Time/TIMESTEP elements, which is shifted lin early to the right every time step: Equations

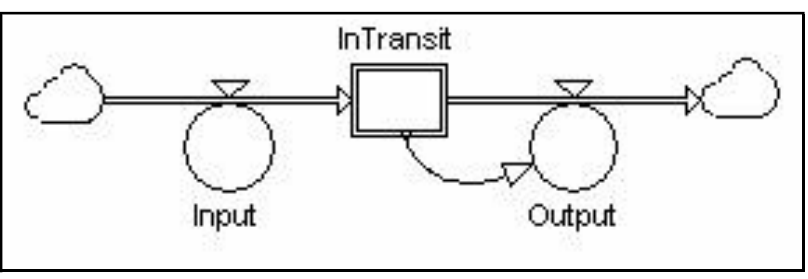

Figure 6. Delay Pipe-Line

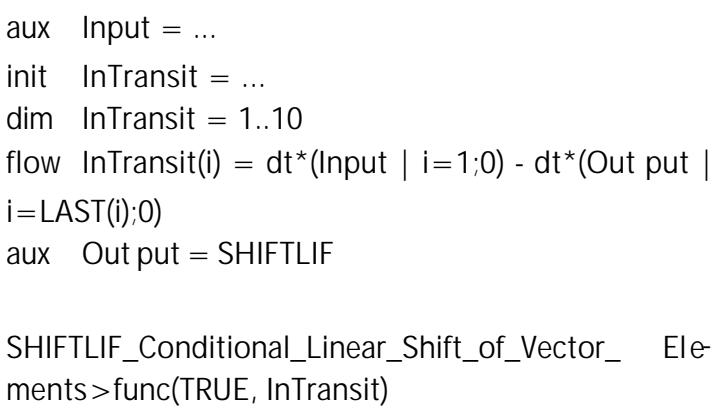

The num ber of el e ments of InTransit should be set equal to the number of time steps in a DelayTime pe riod, i.e., DelayTime/TIMESTEP.

\section{Validation}

When a simulation is ran using historic demand from the year 2002, we can observe some dynamics resulting from the decision making structure used by the managersand in ad dition of un certain de mand.

Table 3. EM SA Finished good's inventory movements at RDC S

\begin{tabular}{cccc}
\hline Week & $\begin{array}{c}\text { RDC } \\
\text { initial }\end{array}$ & $\begin{array}{c}\text { Input } \\
\text { orders }\end{array}$ & Sales \\
\hline 0 & 20000 & 0 & 13083 \\
1 & 6917 & 17189 & 15392 \\
2 & 8714 & 15105 & 15392 \\
3 & 8427 & 19823 & 17701 \\
\hline
\end{tabular}


DOI: http://dx.doi.org/10.22201/fi.25940732e.2006.07n1.003

Supply Chain Dynamics, a Case Study on the Struc tural Causes of the Bull whip Effect

Table 3. EM SA Finished good's inven tory move ments at RDCS(...continuation)

\begin{tabular}{clcl}
\hline Week & $\begin{array}{c}\text { RDC } \\
\text { initial }\end{array}$ & $\begin{array}{c}\text { Input } \\
\text { orders }\end{array}$ & Sales \\
\hline 4 & 10549 & 8096 & 12884 \\
5 & 5761 & 17224 & 15157 \\
6 & 7849 & 15086 & 15157 \\
7 & 7779 & 19545 & 17431 \\
8 & 9893 & 15285 & 16501 \\
9 & 8678 & 22162 & 19413 \\
10 & 11427 & 18910 & 19413 \\
11 & 10925 & 24978 & 22325 \\
12 & 13578 & 15680 & 19314 \\
13 & 9945 & 25939 & 22723 \\
14 & 13161 & 22205 & 33723 \\
15 & 12643 & 29248 & 26131 \\
16 & 15760 & 32484 & 29574 \\
\hline
\end{tabular}

In table 3 we can see the stock move ment in the RDCs. The ini tial in ven tory is 20,000 units. Dur ing the first week we have no arrivals but sales of 13,083 units, resulting in a closing inventory of 6,917 units. How ever, dur ing the first week the distribution manager orders finished goods from the DC up stream to re turn to the planned stock lev els and cover expected future productdemand. The shipment from DC to RDC happens during the week. Therefore, at the end of the week the RDC restores it's the planned stock levels. In effect, dur ing the fol low ing week, new de mand for 15,392 units is served and 17,189 units of stock are re ceived, reach ing a final in ven tory of 8,714 units.

Given the motive of this business, it is not possible to count on the supply of backorders either. If during a given week demand exceeds inventory on hand, the supplier manager only serves as much as possible, and does not consider the short age for later.

It is im por tant to see that dur ing the ini tial moments of the simu la tion, we start from ini tial in ven to ries (pa ram e ters), and after a few mo ments the model reaches a warm-up state that corresponds more to the evo lu tion of the sys tem than to the initial val ues. There fore, we will con sider only the be hav io ur of the sys tem after the $10^{\text {th }}$ week.

In fig ure 7 we show the cus to mer ser vice level. The dotted line rep re sents the fore cast value and in green we have the 'real' demand. The continuous line represents sales: since it coincides with the de mand, it is covered be hind. There fore, the model shows that given the heuristicpolicies from the supply chain managers during the year 2002 , no short age to cus to mers was expe ri enced.

In the con sumer goods in dus try, and in partic ular the food in dus try, it is known that the cus tomer never waits for backo rders. There fore, the as sump tion of 2002 demand to test the model is

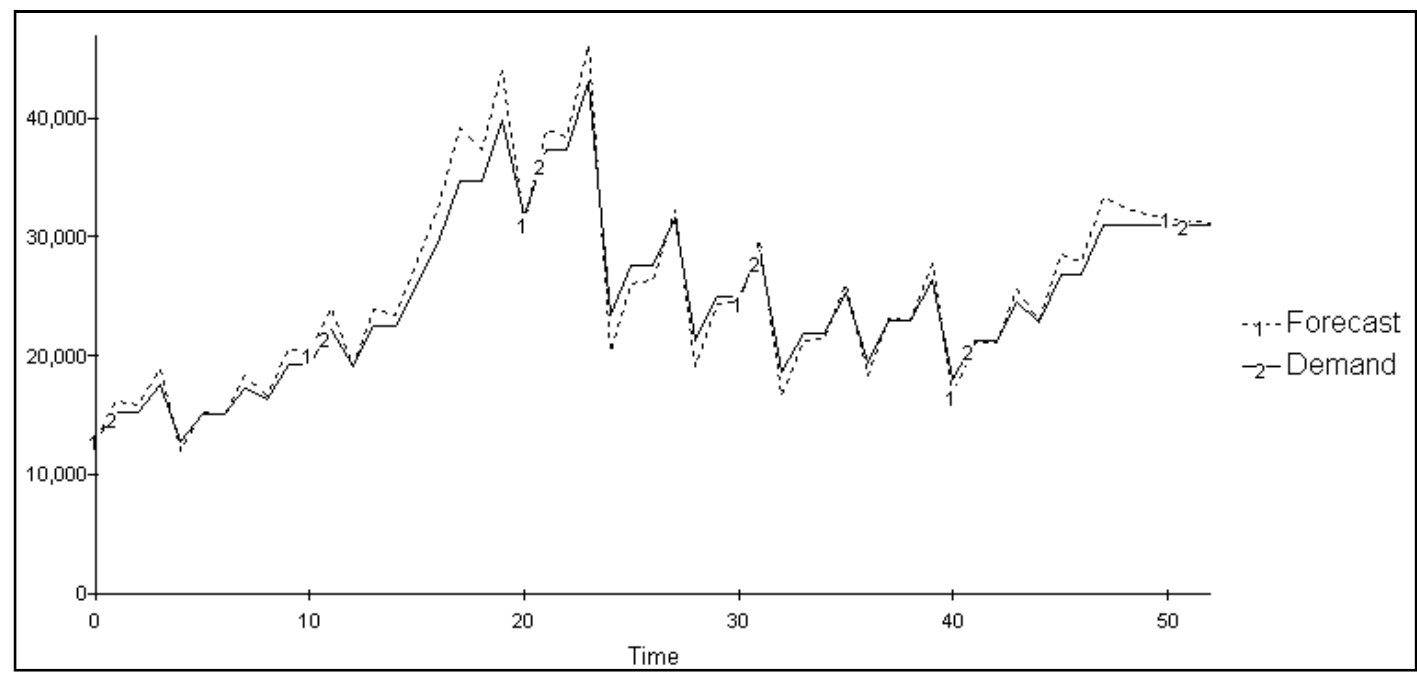

Figure 7: EM SA Customer service and demand fore cast 
mean ing ful to pro vide an in terpre ta tion. How wer, the com pany only has re cords about sales and not 'real' de mand. Since we use sales as input for the forecast, a bias can be in tro duced. It can hap pen that a low fore cast causes lost sales re sult ing in a difference between sales and 'real' demand. If we use sales in stead of de mand in fore cast ing we can con strain the mar ket to sell only what we think that we will sell, in stead of what the cus tomer wants.

If we an a lyze the in ven to ries graph, fig ure 8 , we can observe that high inventories are held, and therefore a cost of inventories derived from the heuristic policies from the sup ply chain man ag ers.

In figure 8 we can also see high raw material stock positions in comparison with the finished goods inventories. This can be caused because: first, the de liv ery time is more than one week; and secondbecause the coverage policy is one week. These factors together can cause oscillations like the ones shown in the graph, since when the purchase man ager de cides not to ask for ma te ri als, we reach the safety stock limits and a big order is placed lead ing to excess in ven tory.

Also, in fig ure 8 , since the stocks have a noisy initial value we can see that it takes around 10 weeks to dis si pate, and then the 'real' be hav io ur of the sys tem ap pears.

According to the current heuristic policies, inventories follow a similar behaviour to the one described by the demand signal. Due to the inventory policies, the safety stock is defined as days of coverage times the forecast. Inventories peak between weeks 15 and 25 which coincides with the summer. Notice that inventories are ap prox i mately half of de mand. This is be cause the coverage pol icy is 3 days of de mand.

Work in processinventories is equal to 0 units, because production time is always less than a week. There fore, noth ing is in pro cess at the end of every week.

From fig ure 8 it is pos si ble to see that fin ished goods inventories at the RDCs move before the fin ished goods at the DCs. In fact, with one week of phase lag. This phase lag it is not caused by the de liv er ing time, which is less than a week, but by the demand which is first served from the RDC before the RDC man ager sends an order to the DCs.

We can also see in fig ure 8 that we do not have any nega tive stock. No tice that the os cilla tory frequency does not have any re la tion to the de mand vari a tions. De mand is clearly sea sonal dur ing the year, with peaks during the summer between weeks 15 and 25. This os cillatory dis tortion is explained next.

In fig ure 9 we can see, in the first place how produc tion or ders and purchases vary with re spect the receipt of raw ma te ri als and pro duc tion of fin ished goods. Purchase and production variability are caused by the time delay and/or the lack of raw material to pro duce.

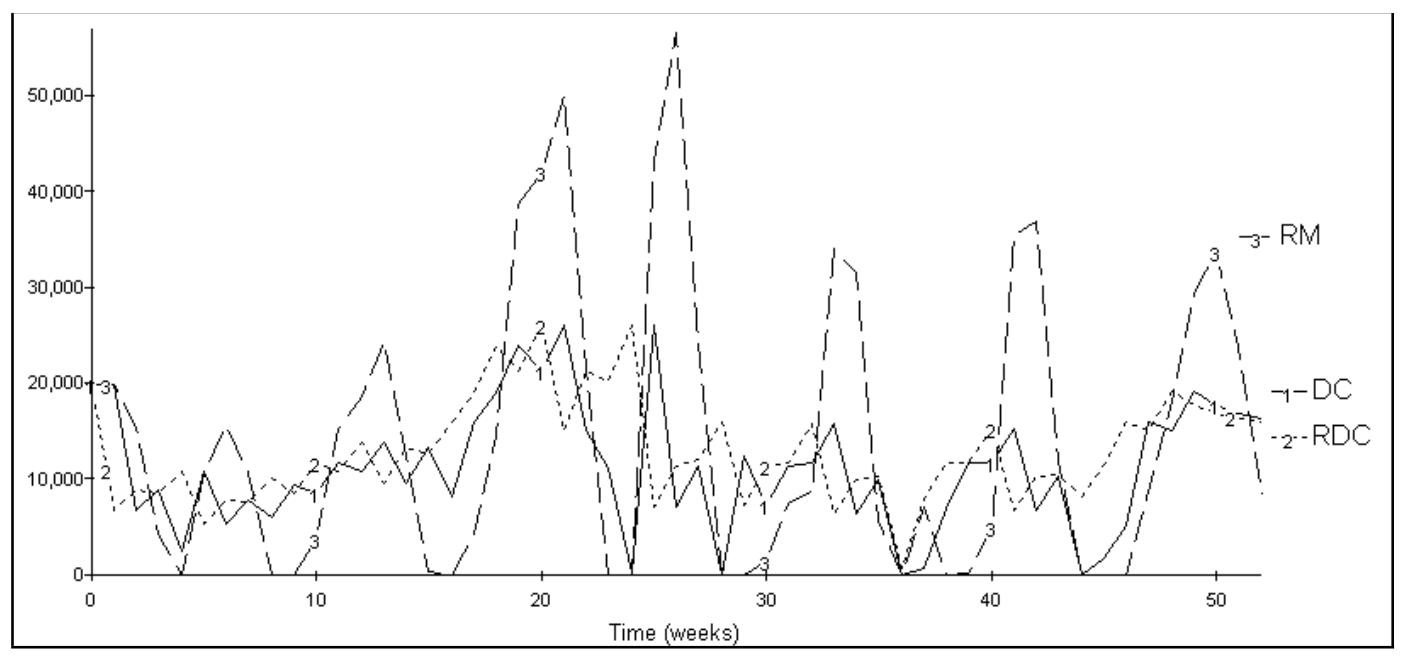

Figure 8: EMSA DC, RDC and RM Inventories 


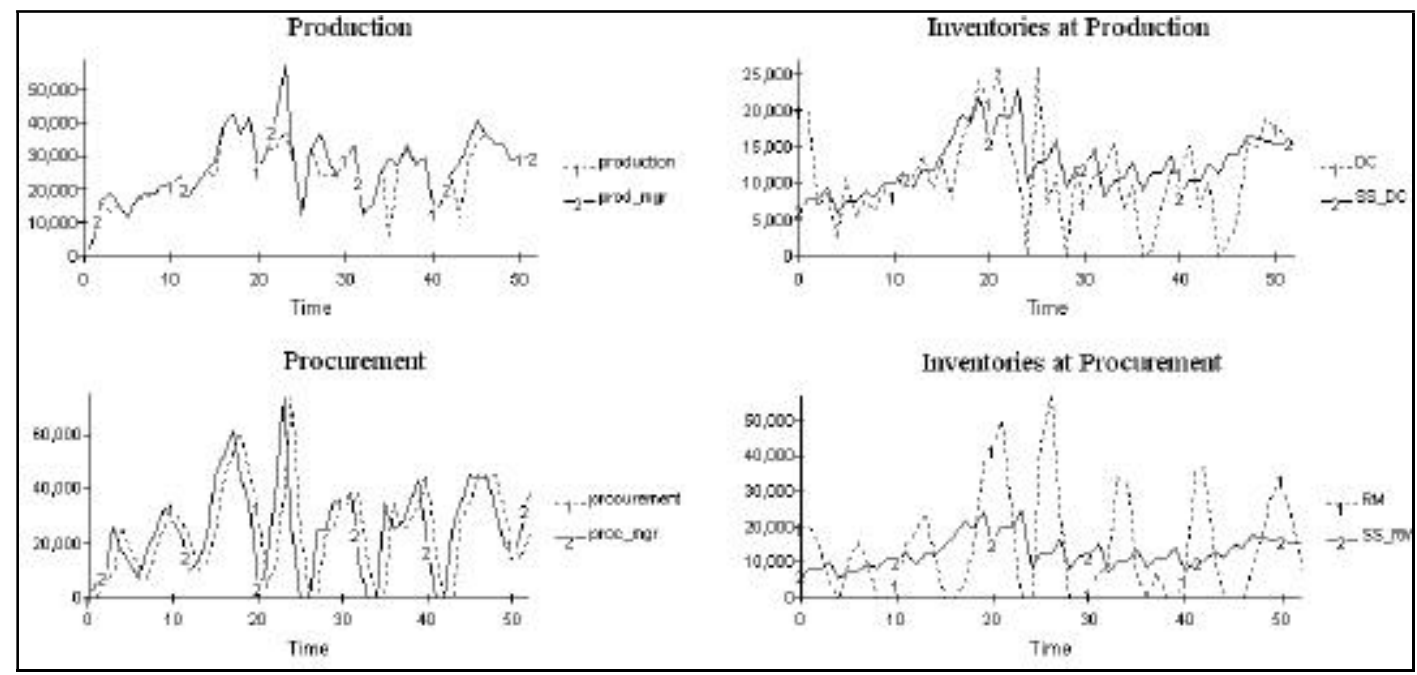

Figure 9: EM SA Production and procure ment plans and execu tion

In figure 9 , in relation to production orders, we can see a per fect ex e cu tion of pro duc tion or ders with the ex cep tion of week 45 . Due to a short age of raw ma te rial, it is not pos si ble to pro duce the full requirement coming from the production manager. This raw material shortage produces a re duc tion of fin ished goods in ven to ries to al most 0 in the same week. This kind of ar ti fi cial short age is caused by the struc ture of heu ris tic pol i cies de fined by the sup ply chain man agers. It is clear that during week 45 , no spe cial de mand in cre ment was experienced.

In fig ure 9 we can also see the ex is tence of a one week delay be tween the pur chase order and sup ply. The Pur chase man ager uses his stock po si tion and fore cast to order. Given the time delay and the time horizon, he produces oscillations in purchase orders, and con sequentlyos cillations in in vento ries even when the safety stock is constant. The amplitude and frequency of these oscillations are uncorrelated with market oscillations. Such uncorrelated oscillations can produce some stock positions near zero, and in particular for the 45th week produce a shortage in production, which affects the DC and RDC inventories, and it is close to im pact ing on cus tomer service.

Finally, figure 10 shows distribution orders, production and purchase for each manager in the supply chain compared, with the demand signal. From the graph we can see that de mand os cil la tions are less than dis tri bution, pro duc tion and purchase oscillations respectively. We see the increased distortion of oscillation manifest the Bullwhip Ef fect, as de scribed by For rester (1962).

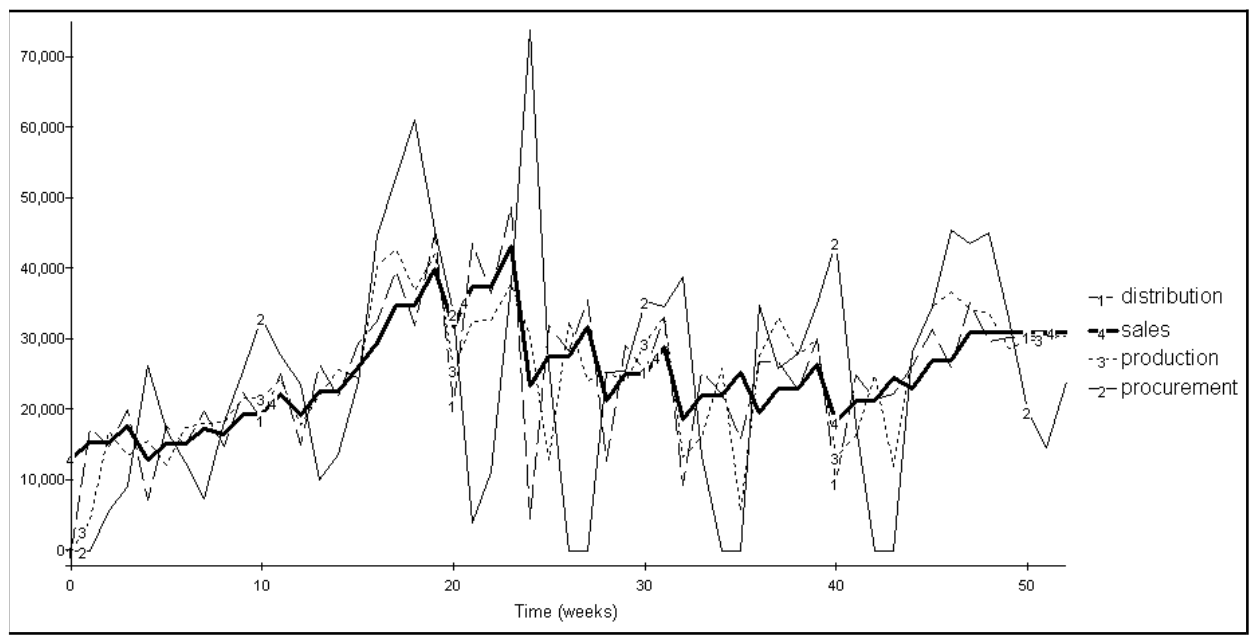

Figure 10: EM SA Bull whip effect 
Finally, figure 10 shows distribution orders, pro duc tion and pur chase for each man ager in the supply chain compared, with the demand signal. From the graph we can see that demand oscillations are less than distribution, production and purchase oscillations respectively. We see the increased distortion of oscillation manifest the Bull whip Ef fect, as de scribed by For rester (1962).

The bullwhip effect can drive wrong decisions when the production or transport capacity is defined. In our model we can see that the ware house for raw ma te ri als needs a ca pac ity of 90,000 units, and even more than that for finished goods. This warehouse capacity not only represents a fixed asset cost but also an inventory cost due to the financial investment. Consider also that the sup pli ers can re ceive or ders that vary from 80,000 to zero units from one month to the next.

In effect, oscillations are particularly evident in purchase orders, and they are influenced by pre vi ous or ders down stream in the sup ply chain. Notice for instance that during the 25th week, demand is low just after the summer season, which is amplified by distribution and production. But during that same week, the purchase man ager re ceives more than 80,000 units due to a pur chase order launched dur ing the mid dle of the sum mer.

The bullwhip effect is attributed mainly to two causes: first, the underestimation of time delays be tween or ders and their ful fil ment, sec ond, to the existence of a motivation among supply chain managers to re quest more ma te rials than needed. Better coordination of the supply chain by managers can be promoted once managers are conscious of the global effects of their heuristic policies in the sys tem.

It is in tu itive to think that a pro duc tion, dis tribution or purchase manager will prefer stability rather than variability. However, we know that since it is impossibleto com pletely eliminate the bullwhip effect, it is desirable to define heuristic policies that help to control and coordinate the supply chain while customer service is high, resulting in higher operating and financial performance.

\section{Business case discussion}

A model that rep re sents the pol i cies of sup ply chain man ag ers can be used as a 'lab o ra tory' where pol icy changes can be tested towards a better supply chain performance, according to pre-defined corporative goals. We prepared for Pepsi-EMSA some initialscenario analysis that included policy changes for the Pepsi $600 \mathrm{ml}$ product. Scenarios included changes in forecastpolicies and purchase or ders. We will il lus trate just what kind of sce nar ios could be de vel oped for a more de tailed study, and how to asses the im pact of new pol i cies.

\section{Changes in purchase orders}

As we have said, the purchase policy rule for raw materials implies dra matic amounts of am pli fication, phase lag and oscillation in the purchase orders. We should expect that a better purchase policy exists in order to minimize order and raw mate rial in ven to ries. Sup pose that weim plement a purchase policy for four sea sons, that is, for each sea son we will de fine a con stant vol ume of weekly purchases.

Figure 11 shows the val ues that raw ma te rial inven to ries can take if a sea sonal pur chase pol icy is adopted. We shall say that the max i mum de mand is for 60,000 units, that is, 20,000 units less than the pre vi ous policy, with the ad van tage of sta bil ity for the sup plier.

A possible problem to define such a seasonal pol icy is the un cer tainty. This sea sonal pol icy be haves rel a tively well for the his toric de mand of the year 2002, but due to its rigidity, the same performance for the fol low ing years is not ex pected.

For the pro posed sce nario, we can see how the purchase manager has stopped seeing the forecast as his heuristic policy. However, notice that the raw ma te rial in ven to ry vari a tion does not have any relationship with the demand variation. In general, the existence of a trade off balance between orders and inventory variability is expected. An optimal policy will manage an equilibrium point where the variation of order quantities will be economical and equivalent to variations in in vento ries. 


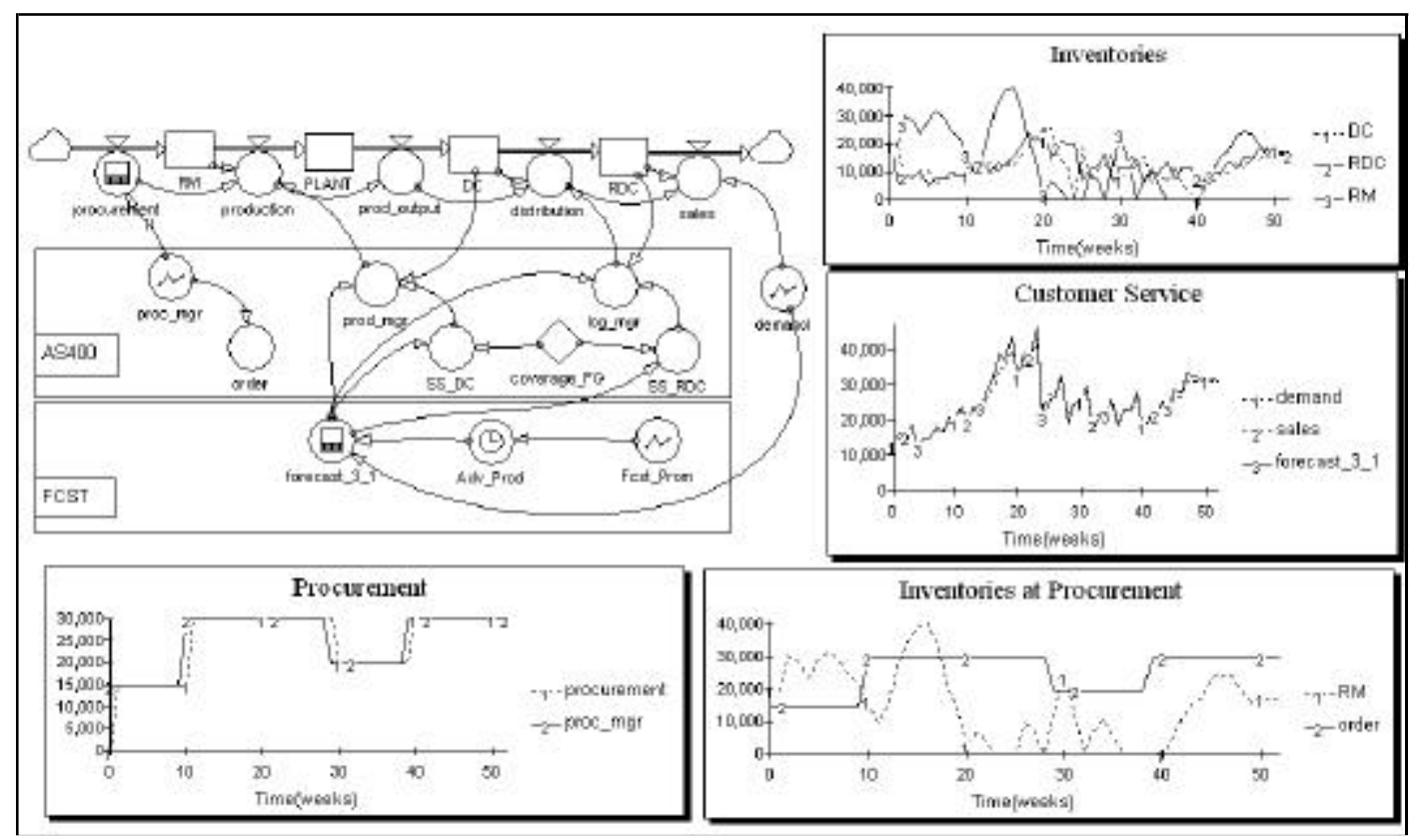

Figure 11: EM SA, Scenario 1

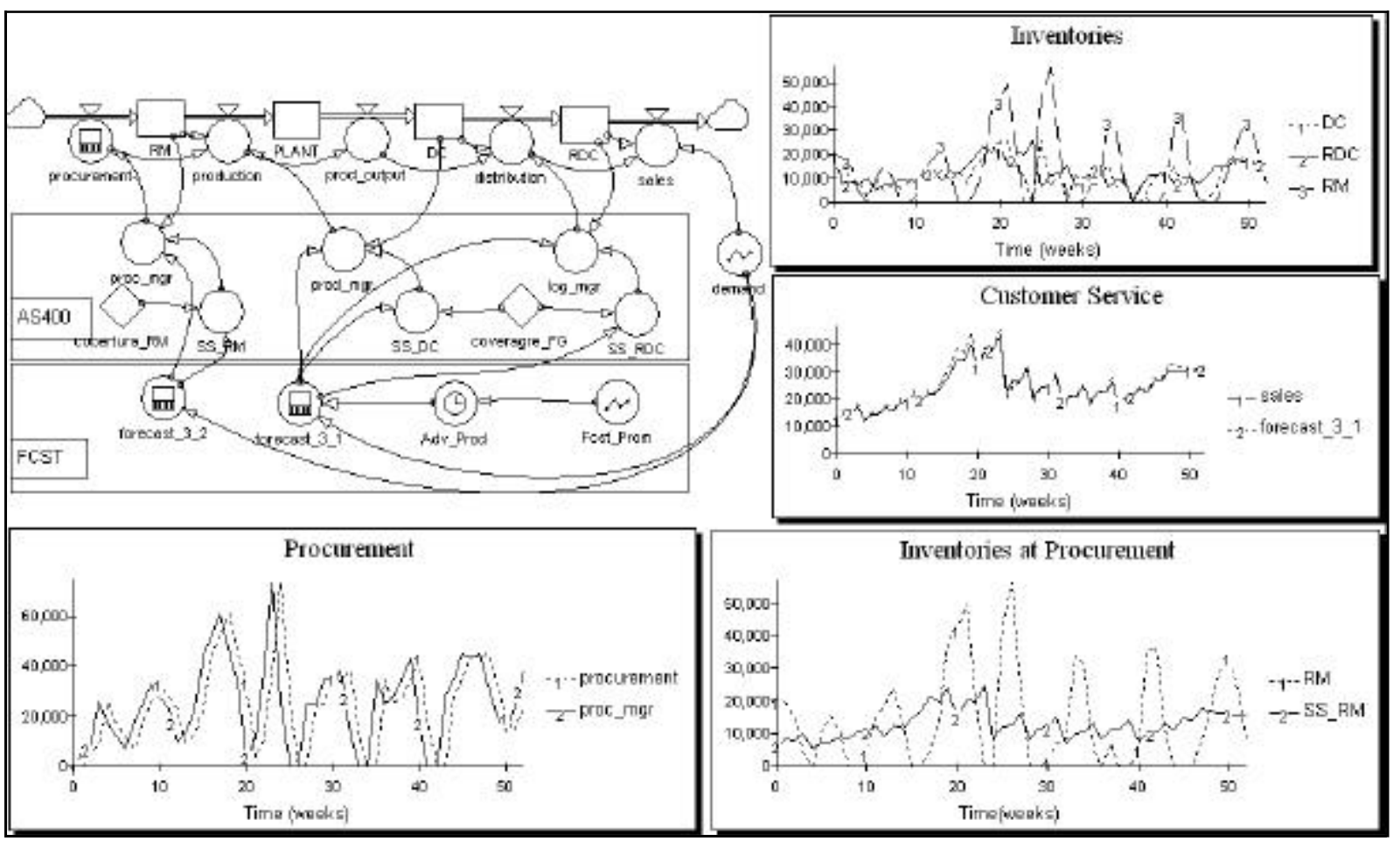

Figure 12: EM SA, Scenario 2

Changes in forecast

Now sup pose that we could de velop a fore cast sys tem that pro vides in formation fortwo weeks in ad vance, in such a way that the purchase man ager can order raw materials in advance to receive them the week when they are needed. Because of this new forecastsystem he de cides to re duce the cov er age from 1 week to 0.5 weeks to gether with the rest of the man ag ers.

Figure 12 shows the impact of this new policy. We no tice that the max i mum in ven tory of raw ma terials is nowap proximately 50,000 units, while the cus tomer ser vice is kept in good health. 
Oscillation of the purchase orders are not eliminated, vary ing from 0 to 70,000 units in side a given season. Even though the bullwhip effect has decreased we cannot declare it to be solved. The inventory costs are still high and the inventory oscillations due to the raw material oscillations cause stresses in different echelons. The oscillation fre quency is con sid er ably high.

Under this sce nario we have re duced the de livery time from suppliers to one week. Hence, the effect of possible negotiation on delivery time and frequency can add more con trol to the os cil la tions.

\section{Conclusions and further research}

In this paper it was not our in ten tion to de velop a technique to define the best policies, nor the best way to de fine new pol i cies in order to im prove supply chain behaviour. Our in ten tion was to define a model where the main dynamics causing Bull whip Ef fect may be stud ied in order to com prehend the cause-effect relationshipsbetween policies, information flows and decision rules of a given sup ply chain. We have shown that is pos si ble to build such a model and to cap ture with rel a tive simplicity but high degree of ab strac tion the complexi ties of a Sup ply Chain.

However, due to its simplicity, the model is lim ited in dif fer ent ways. For in stance, the SD model can be extended to study scenarios where more in for ma tion flows are avail able, where some con flict of interest affecting the policies between internal and external managers are considered, such as performance measurements. Also the model may be used to study the particularities of different industries and establish comparisons across industries, to study the influences of different forecast methods as well as consen sus meet ings, etc. Consequently, in this paper, and for the sake of brev ity we have only fo cused in de scribe a busi ness case where a SD model was cre ated to il lus trate and ana lysea particular sit u a tion, but not to solve the Bull whip Ef fect. What is in tended on this paper is to emphasize methodology used to examine a particular problem, especially be cause in our opin ion, and we coincide with many other authors, the Bullwhip Effect is a problem concerned with the in formation flowand pol icyalign ment.
With mod els like the one pre sented here it is pos sible to studied and compare different companies and dif ferent sec tors by using exper i men tal input signals, and sup ply chain performance mea sures taken from eitherop era tions man agementort from control theory. Unfortunately, the space here is short to de scribe those meth ods in de tail but use ful ref er ences may be found in Villegas (2005).

Finally, it is im por tant to say that even when the model's calibration process has not been described in de tail in this paper it is in gen eral pos si ble to calibrate a model of this complexity to match many data samples. What is important of SD models, as it has been stated in the field, is that they represent the main cause-effect dynamics that generate a given system's behaviour. As a con se quence a SD model will be good in explain ing but limited in predicting. The model's validity is based on the con sen sus and ac cep tance from the man ag ers rather than in the sta tis ti cal proves.

\section{Acknowledgments}

We would like to thank the anon y mous ref er ees for their helpful suggestions that have allowed us to im prove the expo si tion of this re search

\section{References}

Dejonckheere J., Disney S.M., Lambrecht M.R. and Towill D.R. (2002). Transfer Function Anal ysis of Fore casting Induced Bull whip in Supply Chains. International Journal of Production E conomics, 78, pp.133-144.

Dejonckheere J., Disney S.M., Lambrecht M.R. and Towill D.R. (2003). Measuring and Avoiding the Bullwhip Effect: A Control Theoretic Approach. European Journal of 0 per a tional Research, 147, 3, pp.567-590.

Dejonckheere J., Disney S.M., Lambrecht M.R. and Towill D.R. (2004). The Impact of Information Enrichment in the Bullwhip Effect in Supply Chains: A Control EngineeringPerspective. European Journal of Operational Research, 153, 3, pp.727-750

Doyle J.K. and Ford, D.N. (1998). Mental Models Concepts for System Dynamics Research. System Dynamics Review, 14, 1, pp. 3-29. 
Forrester J.W. (1962). Indus trial D ynamics. USA: The MIT Press.

Naim NM., Childerhouse O., Disney S.M. and Towill D.R. (2002). A Supply Chain Diagnostic Methodology: Determining the Vector of Change. Computers \& Industrial Engineering, 43, pp.135-157.

Lee H., Padmanabhan V. and Whang S. (1997a). Infor ma tion Distor tion in a Supply Chain: The Bullwhip Effect. Management Sciences, 43, 4, pp.546-558.

Lee H., Padmanabhan V. and Whang S. (1997b). The Bullwhip Effect in Supply Chains. Sloan Management Review, Spring, pp.93-102.

Lane D.C. (2001). Rerum Cognoscere Causas: How do the Ideas of System Dynamics Relate to Ttraditional Social Theories and the Voluntarism/determinism Debate? System Dynamics Review, 17, 2, pp. 97-118.

Sterman J. (1989). Modelling Managerial Behaviour: Misperceptions of Feedback in
Dynamic Decisions Making Experiment. $M$ anagement $S$ cience, 35, 3, pp. 321-339.

Sterman J. (2000). Business Dynamics. USA: MacGraw-Hill.

Sterman J. (2002). All Models are Wrong, Reflec tions on Becoming a Systems Scientist. Systems Dynamics Review, 18, 4, pp. 501-531.

Towill D.R., Wikner J.J. and Naim M. (1991). Smo othing Supply Chain Dynamics. International Journal of Production Economics, 22, pp.231-248.

Towill D.R. (1995). Industrial Dynamics Modelling of Supply Chains. International Journal of Physical Distribution Logistics M anagement, 26, 2, pp.23-42.

Villegas F. (2005). Supply Chain Dynamics, Structural Causes of the Bullwhip Effect. Working Paper, Manchester Busi ness School, Univer sity of Manchester.

\section{Semblanza de los autores}

Felipe A. Villegas-M orán. Labora en el Departamento de Dirección de Operaciones en la Manchester Busi ness School, Univer s ity of Manchester en el proyecto de "Supply Chain Dynamics". Es investigador en The School of Manage me nt, Univer sity of Edinburgh en el proyecto de "Transfer Prices in Multinational Supply Chains". Su investigación doctoral es sobre la implantación de sistemas de información en cadenas de suministro en la Facultad de Ingeniería de la UNAM.

0 ctavio Carranza. Obtuvo el Premio Nacional de Logística 2005, labora en el Departamento de Logística y Distribución en la Escuela de Ciencias Contables Económico Administrativas, Universidad Panamericana, México. Es doctor en dirección de operaciones por la Universidad de Navarra, España y autor del libro "Mejores prácticas logísticas".

Juan P. Antún. Obtuvo el Premio Nacional de Logística 2005. Actualmente es investigador y profesor titular del seminario de investigación en logística empresarial MIT/DEPFI/UNAM, en el Laboratorio de Transporte y Sistemas Territoriales de la Coordinación de Ingeniería de Sistemas del Instituto de Ingeniería, UNAM. Asimismo, es consultor en logística estratégica e internacional, profesor de logística internacional MAE/ITAM e instructor externo del Instituto de Desarrollo Exportador BANCOMEXT. 